$\xi=-1$ 圆

\title{
Cloud Based Gamification Model Canvas for School Information Management
}

\author{
M Nordin A Rahman*, Jazurainifariza Jaafar, M Fadzil A Kadir, Syadiah Nor Shamsuddin, \\ Syarilla Iryani A Saany
}

Faculty Informatics \& Computing, University of Sultan Zainal Abidin, Besut Campus, 22200, Besut, Malaysia

*Email: mohdnabd@unisza.edu.my

\begin{abstract}
Information management especially related to teaching and learning materials is an important application in school in order to bring education system more effective and systematic. Modern education requires fundamental changes in current education system platform for ensuring teaching method becomes more efficient. The challenges of current school information management are non-integrated system, difficulty in configuration and deployment as well as complexity of storage provision. These issues reduce the motivation among teachers to participate in sharing teaching and learning materials in school information management system. This article proposes a gamification model canvas framework for school information management under cloud computing environment. The aim is to provide a method for encouraging the teachers to share their teaching materials. Motivation element provided in model canvas method such as dynamics, behavior, component and aesthetic are used in the proposed framework. With the proposed framework, a cloud based prototype will be developed and can be used by schools.
\end{abstract}

Keywords: Cloud Computing; Gamification; Motivation; School Information Management.

\section{Introduction}

The rapid development of information technology contributes positive impacts of teaching method in education system. Information management gives positive impact to school management in driving education process become more effective and systematic. School information management not only introduce new innovation technology but also consider widespread demand from education stakeholders especially the management of school and teachers.

Nowadays, gamification becomes a popular approach in education system. Gamification is defined as the use of game design elements in non-games context [1,2]. Gamification used game-based mechanics, aesthetics and game thinking to engage people, motivate action promote learning, and solving problem. Gamification can be divided into two types: serious game and gameful design [3].

Serious games exploit game mechanics and game thinking to educate player in specific instruction. Serious game can be engaged and interacted with the player by using game space or computer browser. Meanwhile, gameful game or also known as gamification use game mechanics to engage player and other activities [3, 4]. The main goal of gamification is to encourage user involvement and create meaningful experience and the most important can give an intense of enjoyment to the user [5, 6].

Cloud computing platform has occurred as a new paradigm in network based service within industrial and application domains. It is a new model of business computing that can provide scalable, quality a service guaranteed and computing platform on demand which can be accessed in any location at any time [7, 8]. Cloud computing delivers more efficient in large storage, memory and performance capacity. Cloud computing can be a part of network server, platform, infrastructure segment, application and services $[9,10]$.

This article discussed several topics to accomplish the goal to motivate teacher in participate in school information management. In Section 2, the article discussed literature review of gamification concept and cloud computing technology. Section 3 will be discussed the proposed gamification model canvas in school information management. In Section 4, the architecture of cloud based gamification information management in school will be explain thoroughly. Section 5 is allocated for conclusion of research work.

\section{Literature Review}

According to the figures release by Ministry of Education (MOE) in $31^{\text {st }}$ July 2016 (www.moe.gov.my), Malaysia has 10180 which consists 7,772 primary schools and 2,408 secondary schools. The overall number of students in Malaysia is 5,074,612 with the total of 200,684 are in preschools, 2,685,403 students are in primary schools and 2,188,525 students are in secondary schools. Meanwhile, the total numbers of teachers in Malaysia are 421,828 which 239,850 teachers serve in primary school and 181,978 teachers are in secondary school. This research are focuses teachers who are teach in primary schools to participate in school information management.

The Ministry of Education in Malaysia has launched an online system called School Management System (SMS) or Sistem Pen- 
gurusan Sekolah (SPS) in January 2015. This SMS has six (6) modules that contains of school information management, school facilities management, school calendar management, system administration management, employee management and studen management [11]. This system is used by schools, State Education Department (SED), District Education Office (DEO) to achieve information related to schools, teacher and students. This system also assists administrator and teachers to manage information and centralize administrative task.

\subsection{Gamification in Education}

Nowadays, gamification technique has been implemented in education sectors to engage user to embrace specific behavior $[12,13]$ The role of gamification, both computer based and traditional method has been known in education which use game mechanics in motivating and engaging students [14]. The main purpose of gamification in education is to teach and pass the knowledge or skills to the students. With gamification, knowledge can be delivered in different way and it can make the students can enjoy some of the subjects ${ }^{15}$. In gamification application development, it is important to define element of game which called game element [16]. There are many ways to classify game element in gamification activity which may give an impact to school information management and so can motivate teachers in sharing education resources. Gamification in education can improve user creativity and draws on the motivational qualities of good games which unlike traditional learning method where it can only deliver information within context [17].

In real environment education, gamification can be applied in order to improve student [13]. Two approach that can be applied on the use of game mechanics in motivating and engaging students: game-like mechanics such as points, badges and leaderboard to support learner progress and interweave some form of enjoyable game playing [14]. Based on these approach, a conceptual architecture for Intelligent Tutoring System (ITS) has been developed including gamification elements as a key components of the system to improve student achievement and enhance learning.

\subsection{Motivation in Gamification}

The aim of any process of gamification in education is to spawn a motivation that drive the users meet the target behavior set by initiator. Motivation can refer as psychological process that responsible to the target behavior. Motivation has defined motive is influence human behavior which allow us to follow a specific goal to get what we want to be [18]. Motivation can be divided into two categories: extrinsic motivation and intrinsic motivation. Extrinsic motivation refers to behavior that can give an external reward for themselves such as money, grade, praise or reputation. Meanwhile, intrinsic motivation refers to person undertakes an activity on its own sake or self-fulfillment not because of some external rewards.

\subsection{Cloud Computing}

Cloud computing technology allows user to access the application and data in remote "cloud" as on demand at any location. It is online activity such as accessing data or using software programs where the user can use in different devices that connected to the Internet [19]. Cloud computing has been defined a set of networks that enable service with quality of service guaranteed and providing scalable of resources $[7,8]$.

Sharing resources in hardware and software can be applied as a platform as application development in cloud computing platform9. The word cloud can be stated in two concepts: virtualization and abstraction [20]. The virtualization is defined as sharing resources and pooling. Meanwhile, abstraction can be stated as a detail system implementation such as application runtime and data store is not considered in physical by user or developer.

In general, cloud computing can be divided into two models: deployment model and service model. Deployment model consists of public cloud, private cloud, and hybrid cloud. National of Standard and Technology of U.S Department of Commerce defined public cloud is used in general public which can be owned, organized and managed in different organization. Public cloud can be used in large industry where can be accessed by any connection and access to the cloud space [21]. Private cloud is exclusive use in single organization which have multiple consumer such as business unit. It can be managed, organized and owned by different organization and exits on or off premises [22]. Community cloud is exclusive used by a specific community or industry that share concern such as security requirement, mission and policy which claims and important by various organization [21, 22]. Meanwhile, for the deployment model are hybrid cloud deals with two or more distinct cloud infrastructure such as public cloud, private cloud or community cloud with unique entities [21, 22, 23] The hybrid cloud is bound together by priority technology that enables applications portability and data.

Service model in cloud computing consists of Platform as a Service (PaaS), Software as a Service (SaaS) and Infrastructure as a Services (IaaS). PaaS is a set of software and provides basic accessories include networks, operating system, development tools and server to allow users in this service to develop application [9, 19]. This platform is designed focus for systems developer.

IaaS is a hardware component that offered for virtual services to users $[19,23,24,25]$. For instance, IaaS manage to provide the hosting operation and transition of selected application infrastructure. When the hosting operation and infrastructure management are off-loading, the user have to maintain ownership and management of their application. Basically, IaaS consists of five layers component: computer network, computer hardware for internet connectivity, platform virtualization environments for running client-specified virtual machines, utility computing billing and service-level agreements.

SaaS is an application or a software running in the cloud platform which provide the service that can be accessed by permission [9] SaaS is hosted as a service to the customer and can be accessed via Internet. The user has limited authority to set up the software and does not have to maintain the software or application.

\section{Gamification Model Canvas Method}

Gamification model canvas is an application that used game mechanism and game thinking in non-environment problem solving [26]. This model is applied in industry to manage human resource, marketing and education. The aim of gamification model canvas is to assist the process of evaluation in game design and develop behavior in non-game context.

In gamification model canvas, there are nine elements that provide positive impact of motivation to the players. Gamification model canvas features consist of platform, mechanics, component, dynamics, aesthetics, behavior, player, cost and revenues (Fig. 1). These features help the developer to create their own gamification environment.

- $\quad$ Platform - it is defined for developer to describe and implement game mechanism.

- Mechanics - to describe the rule of the game with the component for creating dynamic game. E.g. "Answers this survey and get expert level".

- Component - It describes the elements or characteristics of the game to create mechanics or to give feedback to the player. E.g. points, badges, achievement, rewards and etc.

- Dynamics - describes the run-time behavior of the mechanics acting on the player over time. E.g. progression, 
reward, identity and creativity.

- Aesthetics - describe the desirable emotional responses evoked in the player. E.g. narrative, challenge, expression and submission.

- Behavior - describe the behavior of necessary action to develop inside the player in order to get returns from the projects.

- Cost elements - describe the main cost or investment for the development of the game.

- Revenues - describe the economic or social return of the solution with the introduction of gamification.

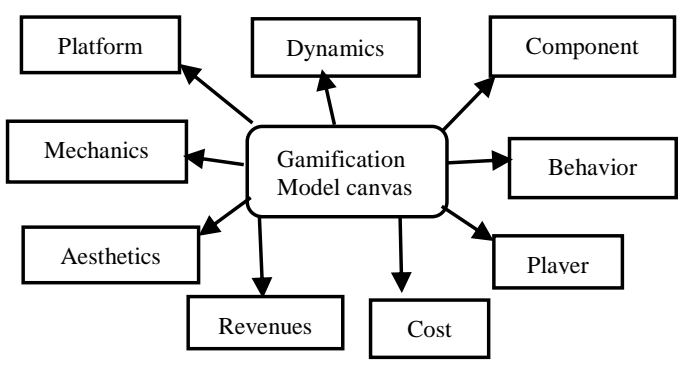

Fig. 1: Gamification Model Canvas Features

\section{Cloud Based Gamification Model Canvas Framework for School Information Man- agement}

Cloud computing is a network computing resources which can be shared by anyone in any located. It can benefit to the education system that apply the concept of open data. In conventional learning management, teachers had faced challenges in sharing educational materials such as examination papers, test, teaching materials and other materials among them. Integration of software, service and asset which own by the schools could provide a new choice of balanced system management, cost and security at the same time to improve the qualities of the services [24, 25].

In education or academic ecosystem, cloud computing technology offers a different service application, platform and infrastructure [23]. By accessing via cloud computing service, school does not need to spend too much cost to buy commercial license [24]. There is free application method which school could apply in information management particularly such as google cloud computing service E.g. Google Apps. Google Apps provides office tools, email and other application for teachers to use in their teaching and learning environments.

In cloud based gamification model canvas framework, we use the concept of Software as a service in supporting school education particularly in information management such as exam materials, classroom notes, assignments, coursework etc. We proposed cloud based gamification model canvas framework for school information management. Gamification model canvas is interrelated with cloud computing approach in school information management to give positive impact to the teacher in engaging collaboration and contribution. It may give an extrinsic motivation to the teacher due participating in school information management. This gamification framework focus on component, behavior, aesthetics and dynamics features that will be embedded into school information management under SaaS concept. These elements are used to give an extrinsic motivation to the teacher in sharing educational materials. When teachers sharing more educational materials, teachers will get a benefit to unlock other educational resources from others teachers.

Fig. 2 shows cloud based gamification model canvas framework in school information management. In this framework, the elements are used in gamification model canvas are component, behavior, aesthetics and dynamic to develop the value in motivation to the teachers and can be denoted as, motivation-element $=\{$ component behavior, aesthetics, dynamic .

Component element in gamification model canvas consists of characteristics that can give feedback to the teachers. This feedback is including teacher's achievement and then is converted into the rewarding token. These feedback parameters are feedback = \{points, badges, achievement, reward\}. These parameters are applied once teacher login into the system and get a points. Teachers will earn one (1) point of every task in school information management and collected into individual point. The point which collected by the teacher will convert to badges and will describe the performance of the teacher. With this achievement, teachers will get rewards to unlock other educational materials shared by others teachers.

Meanwhile, the element of behavior is used to develop necessary actions for participants in order to get returns or benefits from the application. This behavior is needed to improve the challenge in gamification scenario. Three (3) parameters are defined in behavior element and can be denoted as, behavior $=$ \{download, read content, make comments $\}$. To make the application is delighted, teachers can download the content of educational materials from other teachers, read and can make comments of that content.

Aesthetics elements describe the desirable emotional responses evoked in the teachers. This element can give good expression to the teachers when teachers can unlock a new set of shared materials. Two parameters of aesthetics element are defined and can be denoted as aesthetics $=\{$ fellowship, submission $\}$. In this condition, teachers can create fellowship and communicate among other teachers. The parameter of submission used when teacher submit the educational materials in the system and get the points when they submit a new teaching and learning material.

Finally, dynamics element in gamification model canvas describes the run-time behavior of acting on the teacher to create emotional. The dynamics element can gain creativity to the teachers in creating new method of teaching and share with other teachers. In this framework, the parameter of dynamics can be signed as dynamics $=\{$ progression, rewards, productivity, creativity $\}$. The parameter of creativity can describe in creating new teaching environment that can gain students interest in the subject. It also can increase educational environment productivity which is related to creativity parameter. When teachers share their new creativity in teaching method, teachers can see their progression in the system and then get the points in term of creativity element and finally get the rewards.

All the elements of gamification model canvas which are component, behavior, aesthetics and dynamics can give an extrinsic motivation to the teachers in playing part of school information management application.

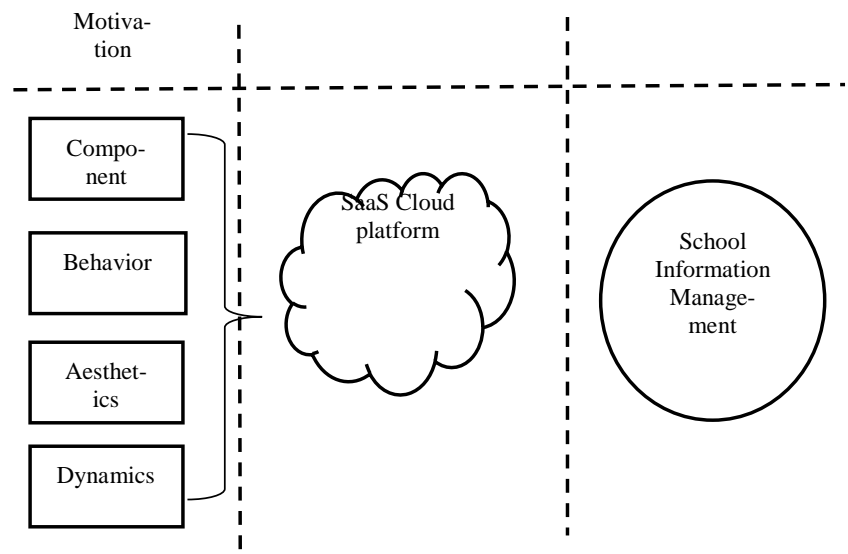

Fig. 2: Cloud Based Gamification Model Canvas Framework for School Information Management 


\section{Conclusion}

The successful of education can be determined by the costeffective in delivering information to the targeted recipients. Problems and motivations faced by teachers in sharing their teachingand-learning materials stimulate school management to make further action based on technology method. This article proposed cloud based gamification model canvas for school information management. It would help and motivate the teachers to share their teaching-and-learning materials effectively. The model also could help the school management to monitor the activity of teaching progress among teachers especially in improving skillsets and knowledge. In upcoming work, a prototype of school information management using gamification technique will be developed. This prototype is developed on private cloud platform as a part to complete the concept of software as a service.

\section{Acknowledgement}

This study is funded by Ministry of Higher Education Malaysia (FGRS/1/2015 - Code: RR143). Special thanks to University of Sultan Zainal Abidin for providing facilities to develop and evaluate the proposed framework.

\section{References}

[1] Deterding S, Dixon D, Khaled R \& Nackle L, From Game Design Elements to Gamefulness: Defining "Gamification" Proceeding of $15^{\text {th }}$ International Academic MindTrek Conference: Envisioning Future Media Environments, ACM (2011), pp. 9-15, http://dx.doi.org/10.1145/2181037.2181040

[2] Watson D, Hancock M \& Mandryk R L., Gamifying Behavior that Leads to Learning, Proceeding Gamification 13 Proceeding of the First International Conference on Gameful Design, Research, and Applications, ACM (2013), pp. 87-90, http://dx.doi.org/10.1145/2583008.2583021

[3] Kapp K M, The Gamification of Learning and Instruction: Game-Based Methods and Strategies for Training and Education, Pfeiffer, (2012)

[4] Laskowski M, Implementation Gamification Technique into University Path: a Case Study, Global Engineering Education Conference (EDUCON), IEEE, (2015), pp.582-586

[5] Kim J T \& Lee W -H, Dynamical Model for Gamification of Learning (DGML), Journal of Multimedia Tools and Application, Vol.74, (2015), pp.8483-8493

[6] Zhoa Q, Application Study of Online Education Platform Based on Cloud Computing, $2^{\text {nd }}$ International Conference of Consumer Electronics, Communication and Network (CECNet), IEEE, (2012), pp. 908-911

[7] Wang B \& Xing H Y, The Application of Cloud Computing in Education Informatization, International Conference on Computer Science and Service System (CSSS), IEEE, (2011), pp.26732676

[8] Wang L \& Laszewki G V, Scientific Cloud Computing: Early Definition and Experience, International Conference on High Performance Computing and Communication, IEEE, (2008), pp.825-830

[9] Bousselhem A, Sadiki T. Security of virtual Network in Cloud Computing for Education, International Conference on Web and Open Access to Learning (ICWOAL), IEEE, (2014), http://dx.doi.org/10.1109/ICWOAL.2014.7009218

[10] Abidin N I A, Zakaria R, Pourbehzad P, Ibrahim O, Zin R M, Majid M Z A \& Mustaffar M, Rahman M S A, Cloud Computing on Project Management to Sustain Natural Environment, Malaysian Journal of Engineering, 26(2), (2014), pp. 269-281

[11] Hassan H, Rahmatullah B \& Nordin N M, Towards School Management System (SMS) Success in Teacher Perception, Malaysian Online Journal of Educational Technology (MOJET), Vol 2 (2014)

[12] Forde S F, Mekleef E D \& Opwis K, Informational vs Controlling Gamification: A Study Design, Proceeding of Symposium on Computer-Human in Play (CHI), Journal of ACM, (2015), pp. 517- 522

[13] Barata G, Gama S, Jorge J \& Gonçalves D, Improving Participation and Learning with Gamification, Gamification Proceeding,
Journal of ACM, (2013), pp. 10-17

[14] Preist C \& Jones R, The Use of Games as Extrinsic Motivation in Education, Proceeding of the $33^{\text {rd }}$ Annual ACM Conference on Human Factors in Computing system (CHI'15), Journal of ACM, (2015), pp. 3735-3738

[15] Minović M, Milovanović M \& Starčević D, Modelling Knowledge and Game Based Learning: Model Driven Approach, Journal of Universal Computer Science, Vol.17, No 9, (2011), pp 1241-1260

[16] González C, Mora A \& Toledo P, Gamification in Intelligent Tutoring Systems, Proceeding of the Second International Conference on Technological Ecosystem for Enhancing Multiculturality (TEEM'14), Journal of ACM, (2014), pp. 221-225

[17] Barata G, Gama S, Fonseca M J \& Gonçalves D, Improving Student Creativity with Gamification and Virtual Worlds, Proceeding of the First International Conference of Gameful Design, Research and Application (Gamification'13), Journal of ACM, (2013), pp. 95-98

[18] Sailer M, Hence J, Mandl H \& Klevers M, Psychological Perceptives on Motivaton Through Gamification, Interaction Design and Architecture(s) Journal, N.19, (2013), pp. 28-37

[19] Kurelović E K, Rako S \& Tomjanović J, Cloud Computing in Education and Student Needs, MIPRO, (2013), pp. 726-731

[20] Sosinsky S, Cloud Computing Bible, Wiley Publishing: IndianaPolis, (2011)

[21] Nabi S A, Gurram D \& Ali M A, Mobile Hybrid Cloud Computing for Educational Instituitions: Mobihybrid EduCloud, International Conference on Innovations in Information, Embedded and Communication System (ICIIECS), (2015)

[22] Mell P \& Grance T. The NIST Definition of Cloud Computing, National Institute of Standard and Technology Special Publication

[23] Alshuwaier F A, Alshwaier AA \& Areshey A M. Application of Cloud Computing for Education, International Conference on Computing and Networking Technology (ICCNT), (2011), pp. 2673-2676

[24] Mariya S, Cloud Computing- an Advance E-Learning Platform of School Education, $14^{\text {th }}$ International Conference on Interactive Collaborative Learning (ICL), IEEE, (2011), pp. 569-570

[25] Chandra D G \& Malaya D B, Role of Cloud Computing in Education, International Conference on Computing, Electronics and Electrical Technologies(ICCEET), (2012), pp. 832-836.

[26] https://uxmag.com/resources/gamification-model-canvas, (2013), [Accessed on $12^{\text {th }}$ December 2016] 